Voix et Images

voixetimages

\title{
Rhétoriques noires et rouges
}

\section{André Brochu}

Volume 34, numéro 3 (102), printemps-été 2009

Trajectoires de l'auteur dans le théâtre contemporain

URI : https://id.erudit.org/iderudit/037671ar

DOI : https://doi.org/10.7202/037671ar

Aller au sommaire du numéro

\section{Éditeur(s)}

Université du Québec à Montréal

\section{ISSN}

0318-9201 (imprimé)

1705-933X (numérique)

Découvrir la revue

Citer ce compte rendu

Brochu, A. (2009). Compte rendu de [Rhétoriques noires et rouges]. Voix et Images, 34(3), 135-140. https://doi.org/10.7202/037671ar d'utilisation que vous pouvez consulter en ligne.

https://apropos.erudit.org/fr/usagers/politique-dutilisation/ 


\author{
P O ÉS I E \\ Rhétoriques noires et rouges \\ $+++$ \\ ANDRÉ BROCHU \\ Université de Montréal
}

Deux éditeurs dynamiques, l'un de littérature générale et l'autre de poésie, nous invitent à une remontée dans le temps. Nota bene (de Québec) réunit pour la première fois en livre les poèmes de François-Xavier Garneau (1809-1866 ${ }^{1}$ ) et Le Noroît publie une anthologie de Louis-Honoré Fréchette (1839-1908). Dans l'un et l'autre cas, on reconnaît le louable souci de rendre accessible le corpus le plus valable de nos origines littéraires.

\title{
GARNEAU AVANT GARNEAU
}

On sait que l'auteur du «Dernier Huron» est avant tout le grand prosateur à qui nous devons ce monument de nos lettres qu'est l'Histoire du Canada. Quelques-uns des poèmes qu'il a publiés, dès l'âge de 21 ans, font tout de même de lui un inventeur de notre tradition poétique, après Michel Bibaud dont le classicisme, souvent bouffon et lourdement inspiré de Nicolas Boileau, n'a pas eu de postérité. FrançoisXavier Garneau est plus proche des romantiques, ou des préromantiques restés fidèles à quelques aspects de la composition classique. On trouve chez lui des expressions convenues comme «l'astre du jour» ou «l'astre des nuits» - parfois plus élaborées («La douteuse clarté de l'astre du silence/Effleurant les coteaux, les bois, la mer immense » [29]) —, de la mythologie, des métaphores grandiloquentes, des formules strophiques recherchées, et surtout des sujets ou des personnages édifiants, empruntés à notre histoire. Sa poésie annonce par là son grand œuvre d'historien.

Le lecteur d'aujourd'hui devra passer par-dessus tout un fatras rhétorique. Toutefois, le paysage thématique nous sollicite encore, malgré ses côtés démodés. Par exemple, la dimension politique omniprésente dresse déjà de façon très

$$
++
$$

1 François-Xavier Garneau, Poèmes, édition intégrale préparée sous la direction de François Dumont, postface de Robert Melançon, Québec, Nota bene, coll. "Cahiers du Centre Hector-De Saint-Denys-Garneau», 2008, $174 \mathrm{p}$. 
alarmante le constat de la fragilité de notre petit peuple. Le poème intitulé "Au Canada» (ou «Pourquoi mon âme est-elle triste?», dans la réédition qu'en fait le Répertoire national de James Huston), après avoir évoqué ce «peuple de héros, [...] un peuple libre et fort» qu'appelle la nature grandiose, déplore plutôt une lamentable réalité :

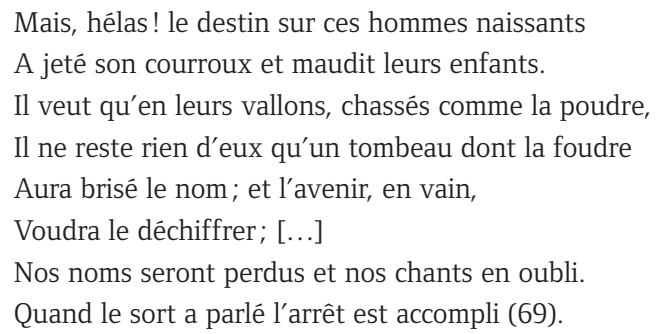

Le reste du poème reprend le même lamento: «Rien de lui ne dira son nom ni sa puissance», "Notre langue se perd....», "Déjà, l'obscurité nous conduit au naufrage», "Nous voyons sans souci venir notre ruine», "On dit: laissons tomber ce peuple sans flambeau,/Errant à l'aventure;/Son génie est éteint et que la nuit obscure/Nous cache son tombeau. » (70) Ce Canada qui est mourant, c'est évidemment le Canada français, une trentaine d'années avant la Confédération qui voudra rendre toute renaissance impossible et qui confisquera même le nom du peuple pour le donner à l'ensemble qui l'écrase.

Il y a une troublante continuité entre le sentiment génosuicidaire de Garneau et celui d'aujourd'hui, où la mondialisation fait de l'assimilation un horizon proche et, pour plusieurs, presque désirable. Garneau le disait bien: «Nous voyons sans souci venir notre ruine.»

Sur le fond d'un tel désespoir, le poète se fait le chantre de valeurs très positives, en particulier de la liberté - la liberté des peuples avant tout, la liberté collective, telle que la Révolution française et la guerre de l'Indépendance américaine l'ont popularisée. Garneau appuie dans plusieurs poèmes la Pologne contre l'envahisseur russe; il évoque dans "Louise» la bataille de la Monongahéla («Monongahla», dans le texte) où les Français vainquent les soldats britanniques, mais perdent un grand homme, Edouard de Chambly, époux de l'héroïne éponyme. Les héros des poèmes ne sont pas de simples individus, comme dans la poésie confidentielle issue du romantisme et du symbolisme, mais les porteurs d'un destin plus grand qu'eux, et ce destin n'est guère réjouissant. Tel est le cas du "Dernier Huron ", la figure la plus célèbre de la poésie garnélienne, qui témoigne, impuissant, de la disparition des siens. Les «Canadiens» peuvent voir dans ce malheur, auquel ils ne sont évidemment pas étrangers, le reflet du sort qui les attend.

Les poèmes de Garneau sont souvent composés de strophes régulières, et, comme dans les chansons, des sortes de refrains, assez massifs, font contrepoids à la linéarité du récit et déterminent une dimension lyrique. Cela dit, cette disposition formelle peut parfois sembler artificielle, et elle ne fait pas oublier les nombreuses faiblesses du texte. Le jeune écrivain, pionnier dans son art, n'arrive pas toujours à 
concilier les exigences de la syntaxe et de la métrique. Pour établir le nombre de pieds voulu, il écrira: «Ils croyent voir, sorti du sein des flammes» (58), «Des Polonais se déployent les rangs» (26) ou "Ils fuyent - leur terreur dans la fuite s'augmente.» (105) Je n'ai pas le souvenir de telles diérèses chez les grands auteurs français.

On trouve aussi des fautes d'écriture, comme cette redondance: «La nuit descend et le jour tombe» (63), ou «La nuit est noire et le ciel sans étoiles» (61), des formulations cocasses: «Et le boulet sanglant, en frappant sa victime/Bondit de joie et court, fier du prix de son crime/En rougir l'herbe des déserts» (52) (le boulet est sanglant avant même de frapper! et il est animé de sentiments humains et de volonté, contrairement à sa victime...), ou encore: «Chacun veut terrasser son terrible adversaire;/Et sous leurs pieds tendus longtemps frémit la terre/Que leur poitrine rase en vain.» (53) Voilà du surréalisme avant la lettre!

Odette Condemine, auteure d'une étude déjà ancienne ${ }^{2}$, a signalé les mérites poétiques de Garneau, mais aussi ses faiblesses stylistiques. Des inversions génératrices de confusion, des négligences de toutes sortes abondent chez lui. Ajoutons à cela les fautes d'accord, de ponctuation et de versification (alexandrins de onze ou de treize pieds...) et les coquilles, qui sont le fait des éditeurs passés, et peut-être présents. Petit exemple, tiré du «Vieux chêne», poème bien connu: «Tandis que le hameau réuni sur la rive/Abandonnait sa joie à l'aide fugitive/Et folâtre des échos.» (130) Au lieu de «aide», les anthologies donnent le mot «aile», plus conforme au bon sens. Qui est responsable de cette leçon fautive? En tout cas, elle a échappé aux présents éditeurs.

Sur les trente poèmes, en fait, il y en a un petit nombre que François-Xavier Garneau semble avoir eu le loisir de retoucher en vue de leur réédition, et ces textes, repris plus tard dans diverses anthologies, présentent souvent une facture plus accomplie que celle qu'on nous donne à lire ici. On se demande pourquoi les éditeurs de cette première édition intégrale des poèmes de Garneau n'ont pas choisi, quand il y avait lieu, la dernière édition revue par l'auteur, moins maladroite et moins fautive que l'originale. Qu'on en juge encore d'après ces vers du poème le plus célèbre, «Le dernier Huron». Éditions Nota bene: «Ô peuple, tu ne seras plus;/Il n'erra plus, bientôt, de toi sur cette rive/Que des mânes inconnus. » (113) Anthologie de Yolande Grisé $^{3}$ : «[...] Il n'errera bientôt de toi sur cette rive/Que des mânes inconnus.» La première leçon, retenue par Nota bene, n'a pas de sens; la deuxième l'emporte non seulement par la clarté, mais aussi par la plénitude du rythme.

Du même poème, comparons le début de la huitième strophe, version originale et version revue (en italique):

Oh! que sont devenus ce peuple et sa puissance,

Et ces guerriers si redoutés,

$$
++
$$

2 Odette Condemine, «F.-X. Garneau - poète», Paul Wyczynski (dir.), François-Xavier Garneau, Aspects littéraires de son œuvre, Ottawa, Éditions de l'Université d'Ottawa, coll. "Publications sériées de l'Université d'Ottawa», 1966, p. 9-43, en particulier p. 40 et suivantes. 3 Yolande Grisé, La poésie québécoise avant Nelligan, Montrêal, Bibliothèque québécoise, 1998, p. 145-149. 
Quand leurs cris de combat et le choc de la lance

Des bois étaient répétés?

Que sont donc devenus, ô peuple, et ta puissance

Et tes guerriers si redoutés?

Le plus fameux du nord jadis par ta vaillance,

Le plus grand par tes cités ${ }^{4}$.

La version plus tardive réduit l'éloquence romantique ( $\mathrm{Oh}$ ! que sont...») et actualise la collectivité en faisant d'elle l'objet d'une apostrophe. Les deux derniers vers, moins concrets que les originaux, sont cependant plus adroits, si l'on excepte la problématique évocation des «cités»... Ils indiquent surtout une nouvelle orientation de l'inspiration, qui délaisse le folklore primitif pour la valorisation de l'instance civile.

J'ignore si l'édition originale d'un texte doit bénéficier d'un privilège absolu, mais il faudrait au moins signaler les versions ultérieures, surtout quand elles comportent de notables améliorations.

Cela dit, sachons gré au Centre Hector-De Saint-Denys-Garneau (que de traits d'union!) d'avoir rassemblé en volume les écrits poétiques de François-Xavier Garneau, et souhaitons qu'un solide établissement du texte facilite un jour la lecture de ces poèmes ${ }^{5}$.

\section{UN POĖTE TRÈS NATIONAL}

L'œuvre poétique de Louis Fréchette, dont le Noroît publie des morceaux choisis ${ }^{6}$, est certainement plus accomplie formellement que celle de François-Xavier Garneau, ou même d'Octave Crémazie. On y retrouve des thèmes semblables: les vicissitudes de l'histoire nationale, la vaillance des héros du passé, la célébration de la liberté des peuples, mais aussi les joliesses d'une nature édénique où semble s'être réfugiée toute la sérénité du monde. Fréchette ajoute à cela un sentiment américain qui fait équilibre à sa fidélité à l'Europe et à la France, ainsi qu'un sens épique qui s'appuie sur l'œuvre colossale de Victor Hugo. Hugo, Lamartine et Béranger (moins célèbre aujourd'hui) ont joué pour nos poètes de l'époque un rôle semblable à celui de Boileau pour Michel Bibaud. C'était normal: on n'invente pas une tradition sans se donner des modèles, quitte à les transformer si possible.

Cela dit, Louis Fréchette me semble moins solliciter la relecture que ses deux devanciers. La réussite sociale de sa poésie y est-elle pour quelque chose? Fréchette

$$
+++
$$

4 Leçon tirée de «Le dernier Huron » sur le site Internet Canadian Poetry Archive, qui reproduit les poèmes du domaine public. Voir, http://www.collectionscanada.gc.ca/canvers-bin/entry?entry_nbr=658\&l=0\&page_rows= 10 \& clctn_nbr=1 5 François Dumont, à la fin de sa présentation, fait état d'une édition critique, en préparation, de l'ensemble des œuvres de François-Xavier Garneau par Yolande Grisé et Paul Wyczynski (dont nous apprenions le décès, en ce début de décembre), de l'Université d'Ottawa. 6 Louis Fréchette, Poète national, poèmes choisis, choix et présentation de Pierre Filion, Éditions du Noroît, coll. «Ovale», 2008, 152 p. 
est bien le poète «lauréat» de son temps, selon l'expression méchante (et envieuse) de William Chapman ${ }^{7}$, et on ne sent pas dans ses vers l'épaisseur d'angoisse ou de malheur de Garneau et de Crémazie. Pourtant, le mot «je» (ou le mot «moi») est généralement absent des poèmes de ce dernier. La dimension individuelle n’est pas pour autant absente en arrière-plan, loin de là. Même chose pour Garneau. Fréchette a une complexion plus heureuse et, même quand il chante un événement tragique, il donne toujours l'impression de triompher. Les luttes politiques débouchent invariablement sur un avenir radieux:

La voix des opprimés s'élève grandissante...

Demain les nations, ô liberté puissante!

En pliant le genou, salueront ton soleil! (39)

Cet optimisme rappelle aujourd'hui les envolées du réalisme socialiste et autres mystifications pieuses. Dans sa préface à la réédition de La légende d'un peuple ${ }^{8}$, Claude Beausoleil, non sans habileté, met sur le compte du lyrisme, dont il emprunte la définition à Jean-Michel Maulpoix, le déni de réalisme chez Fréchette: «[Le lyrisme] déborde de nature l'invention poétique, la transgresse de ses pulsions échevelées. [...] Il aime la fulgurance, les envolées, l'audace dépliant la parole jusqu'aux excès enchevêtrés ${ }^{9}$."

Là où les détracteurs du poète voyaient d'indiscutables défauts, le moderne champion du discours québécois qu'est Beausoleil découvre une puissante inspiration. Voici un exemple parmi tant d'autres du lyrisme de Fréchette. Quand Jacques Cartier, après deux mois de navigation, arrive à l'entrée de ce qui s'appellera plus tard le Saint-Laurent, il découvre un pays plus impressionnant que nature:

C'était le Canada mystérieux et sombre,

Sol plein d'horreur tragique et de secrets sans nombre,

Avec ses bois épais et ses rochers géants,

Émergeant tout à coup du lit des océans! (56)

Ce Canada avant la lettre, sous la plume du poète, a un aspect bien rébarbatif, mais c'est pour mieux mettre en valeur Cartier et ses «compagnons, groupe altier/De fiers Bretons taillés dans le bronze et le chêne!» (60) Le lyrisme qui embellit tout fait ressortir, face à une nature à première vue revêche, la vigueur des héros, mais aussi le réservoir d'énergie émergente d'une Amérique appelée à tous les accomplissements. Le lamento tourne vite à la fanfare.

Dans le choix de poèmes de Pierre Filion, on a droit à une présentation plus posée et plus ordonnée - moins romantique! - que celle de Beausoleil. Le

$$
++
$$

7 Comme on le sait, Chapman a consacré de nombreux articles polémiques au déboulonnage de la statue de son rival en poésie. Voir William Chapman, Le lauréat. Critique des œuvres de M. Louis Fréchette, Québec, Léger Brousseau, 1894, 323 p. 8 Louis Fréchette, La légende d'un peuple, introduction de Claude Beausoleil, TroisRivières, Écrits des Forges, 1989, 284 p. 9 Louis Fréchette, ouvr. cité, p. 16. 
préfacier donne curieusement pour titre «Poète national» à son ouvrage, comme si l'auteur et le titre se fondaient l'un dans l'autre: on ne lira pas les œuvres de Fréchette mais Fréchette lui-même, nimbé dans sa gloire. C'est dire que la littérature s'efface devant celui qui la représente, en un moment précis de son histoire. Le propos de Pierre Filion est de rendre hommage, cent ans après sa mort, à un pionnier de notre littérature tout en reconnaissant que «ses écrits [...] appartiennent à un autre temps, [...] ne sont plus guère étudiés que par des chercheurs qui, le rencontrant sur leur route, ne peuvent éviter le personnage, incontournable homme des lettres de la seconde moitié du XIX ${ }^{e}$ siècle » (146). L'hommage rendu est pourtant fort soigné et permet un survol intéressant de l'œuvre; le commentateur a fort habilement présenté chaque recueil et démêlé l'écheveau des reprises de textes, fréquentes de l'un à l'autre.

Entre les positions de Beausoleil et de Filion, le lecteur pourra se retremper dans les eaux du romantisme québécois tel que Louis Fréchette l'assume, avec le grésillement un peu agaçant de son enthousiasme sans doute, mais aussi une certaine plénitude formelle, une rhétorique soutenue et parfois convaincante. Le mérite - et le tort, tout à la fois - de Fréchette est d'avoir accordé un traitement hugolien, donc grandiose, à un peuple dont le destin ne justifiait pas tant d'éclat. 